\title{
Advillin is a tuft cell marker in the mouse alimentary tract
}

\author{
Anna-Lena Ruppert ${ }^{1} \cdot$ Maryam Keshavarz ${ }^{2} \cdot$ Sarah Winterberg $^{1} \cdot$ Johannes Oberwinkler $^{3} \cdot$ Wolfgang Kummer $^{2}$. \\ Burkhard Schütz ${ }^{1}$ ]
}

Received: 3 March 2020 / Accepted: 25 June 2020 / Published online: 2 July 2020

(c) The Author(s) 2020

\begin{abstract}
Tuft cells are a rare population of chemosensory cells at the mucosal surface epithelia of hollow organs. Their name-giving morphological feature is an apical tuft of stiff microvilli. Accordingly, the actin-binding protein, villin, was identified as one of the first tuft cell markers in immunohistochemical analysis. Unfortunately, villin expression is not restricted to tuft cells, but is also prominent e.g. in enterocytes, which limits the use of this gene as a marker and as an experimental tool to genetically target tuft cells. Here, we report that the villin-related protein, advillin, is a specific tuft cell marker in the gastro-intestinal and biliary tract epithelia. In situ hybridization and immunohistochemistry revealed that advillin expression, unlike villin, was restricted to solitary cholinergic tuft cells in the mucosal linings of the small and large intestine, and in the gall bladder. In the glandular stomach, villin and advillin mRNA were present in all epithelial cells, while detectable protein levels were confined to solitary tuft cells. Advillin expression was no longer detectable in the mucosa of the intestinal and biliary tract from Pou $2 f 3$ deficient mice that lack tuft cells. Finally, crossing Avil-Cre transgenic mice with a double-fluorescent reporter mouse line resulted in specific targeting of gastro-intestinal and biliary tuft cells. Our analysis introduces advillin as a selective marker and tool in histological and functional analysis of the alimentary tract tuft cell system.
\end{abstract}

Keywords Doublecortin-like kinase $1 \cdot$ Intestine $\cdot$ Biliary tract $\cdot$ Immunohistochemistry $\cdot$ In situ hybridization $\cdot$ Villin

\section{Introduction}

Tuft cells, also known as brush cells, are columnar, often flask-shaped cells, and found scattered in the simple surface epithelia of endoderm-derived hollow organs. Originally, they were identified in an electron microscopic analysis of the rat trachea (Rhodin and Dalhamn 1956), and

Electronic supplementary material The online version of this article (doi:https://doi.org/10.1007/s10735-020-09893-6) contains supplementary material, which is available to authorized users.

Burkhard Schütz

schuetzb@staff.uni-marburg.de

1 Institute for Anatomy and Cell Biology, Philipps-University, Robert-Koch-Straße 8, 35037 Marburg, Germany

2 Institute for Anatomy and Cell Biology, Justus-Liebig-University, Aulweg 123, 35385 Gießen, Germany

3 Institute for Physiology and Pathophysiology, Philipps-University, Deutschhausstraße 1, 35037 Marburg, Germany subsequently also observed in intestine and gall bladder (Luciano and Reale 1969; Trier et al. 1987). A characteristic, and hence name-giving morphological feature is the presence of an apical tuft of thick and straight microvilli, that reaches into the lumen of the hollow organ. These microvilli contain axial bundles of actin filaments with elongated rootlets of cytoplasmic filaments, which often terminate close to the cell nucleus.

In the 1990s, immunohistochemistry with antibodies against villin and fimbrin, two actin filament crosslinking proteins, led to an intense staining of the tuft cell apex in the rat major pancreatic duct, submandibular gland, trachea, and intestine (Höfer and Drenckhahn 1992). Although the use of villin-antibodies allowed unequivocal identification of tuft cells in the first three of these sites, in the intestine the whole enterocyte brush border was labeled, making antibodies against villin not well suited as a selective tuft cell marker at this location (Höfer and Drenckhahn 1992). Also, other structural marker proteins, like cytokeratin-18 and $\beta$-tubulin, were found highly, but not selectively expressed by tuft cells (Bezençon et al. 2008; Höfer and Drenckhahn 1996; Schütz et al. 2015, 2019). 
A major advancement was reached when tuft cells were found to share molecular features with taste cells in the oral cavity. Several members of the taste transduction pathway, e.g. $\alpha$-gustducin (Höfer et al. 1996), phospholipase C isoform $\beta 2$ (Bezençon et al. 2007), and transient receptor potential cation channel subfamily M member 5 (TRPM5) (Kaske et al. 2007) were identified in gastro-intestinal tuft cells, suggesting a function of this cell type in chemoreception (Finger and Kinnamon 2011). Microarray and RT-PCR analysis of small intestinal cell fractions enriched in tuft cells from mice expressing enhanced green fluorescent protein (EGFP) under the control of the Trpm5 promoter (Bezençon et al. 2007) subsequently uncovered another structural marker, advillin, whose expression was found to be restricted to tuft cells (Bezençon et al. 2008).

Advillin, initially named p92 (Marks et al. 1998), is a member of the gelsolin/villin superfamily of actin regulatory proteins. Advillin expression pattern analysis suggested that it is expressed almost exclusively by sensory neurons during development and in adulthood (Chuang et al. 2018; Hasegawa et al. 2007). Recently, Avil promoter-driven expression of either Egfp or Cre-recombinase extended the Avil expression pattern to diverse sets of central and peripheral neurons, including all neural crest-derived ganglia (Hunter et al. 2018). In another mouse line expressing Cre-recombinase under the control of the Avil promoter, also taste buds in the circumvallate papilla stained positive (Zurborg et al. 2011).

Since mouse advillin and villin share about 59\% identity on the protein level (www.ensembl.org), it was speculated that published immunohistochemical staining of tuft cells with anti-villin antibodies did not represent true expression, but resulted from cross-reactivity with advillin (Bezençon et al. 2008). Together with the reported tuft cell-specific presence of Avil mRNA in the mouse small intestine (Bezençon et al. 2008), this led us to compare the expression profiles of villin and advillin in the mouse gastro-intestinal and extra-hepatic biliary tract on a cellular level in tissue sections using sensitive in situ hybridization and immunohistochemistry. In addition, the suitability of the afore-mentioned Avil-Cre mouse line to specifically target gastro-intestinal and biliary tuft cells was investigated.

\section{Materials and methods}

\section{Mouse strains and animal procedures}

Bacterial artificial chromosome-transgenic mice that express EGFP under the control of the choline acetyltransferase (Chat) promoter (Schütz et al. 2015; von Engelhardt et al. 2007) were obtained from in house breeding. POU domain, class 2, transcription factor 3 (Pou2f3)-deficient mice (named Pou $23^{-l-}$ throughout the study) (Matsumoto et al. 2011) were obtained from the Monell Chemical Senses Center (Philadelphia, PA, USA) and maintained in house. A double-fluorescent Cre reporter mouse line, mT/ $\mathrm{mG}$ (Muzumdar et al. 2007), was obtained from JaxMice (B6.129(Cg)-Gt(ROSA)26Sor tm4(ACTB-tdTomato, -EGFP)Luo /J, stock no. 007676, The Jackson Laboratory, Bar Harbor, ME, USA). A mouse line that expresses Cre-recombinase under the control of the Avil promoter (Avil-Cre, European Mouse Mutant Archive repository, Id EM:05542; Infrafrontier GmbH, Neuherberg, Germany) (Zurborg et al. 2011) was obtained from the Institute for Pharmacology, University of Heidelberg (Heidelberg, Germany). All mice were housed in groups of 3-6 under specified pathogen-free conditions. They were kept on a $12 \mathrm{~h}$ light/ $12 \mathrm{~h}$ dark cycle and had access to food and water ad libitum. The genotypes of all mice were verified by PCR using genomic DNA obtained from ear biopsies, according to published protocols supplied by the vendors (The Jackson Laboratory) or donators (H. Monyer, Heidelberg, Germany, for ChAT-EGFP mice; I. Matsumoto, Tokyo, Japan, for Pou2f3 mice; P. Heppenstall, Monterotondo, Italy, for Avil-Cre mice). All animal procedures were conducted in accordance with EU Directive 2010/63/EU for animal experiments, the German Animal Protection Law, and received methodological and ethical approval by the local animal welfare officer (protocols: Ex-15-2016, Ex-14-2018, 641-M). A minimum of three mice of both sexes at 12-16 weeks of age were used for all analyses.

\section{Tissue harvesting for histological analysis}

All mice were sedated by inhalation of isoflurane (Forene, order-no. B506, AbbVie Deutschland GmbH \& Co. KG, Wiesbaden, Germany) and sacrificed by cervical dislocation. For the visualization of native EGFP fluorescence, organs were dissected, cut open, mounted flat in a droplet of $0.9 \%$ saline (2350748, B. Braun Melsungen AG, Melsungen, Germany) on a microscopic slide, and cover-slipped. For in situ hybridization (ISH) and immunohistochemistry (IHC), the vallate papilla was identified at the back of the tongue and removed with surrounding muscle tissue. The stomach was opened along the large curvature and the content washed out. The gall bladder was left attached to pieces of surrounding liver tissue. Tissue pieces from duodenum (including pancreas), jejunum, ileum and colon, all $0.5-1 \mathrm{~cm}$ in length, were quickly dissected. Lumbar dorsal root ganglia were identified lateral from the spinal cord and dissected after opening the spine from the dorsal side caudal of the 12th rib. The tissues used for ISH were submerged in TissueTek compound (4583, Sakura Finetek Europe B.V, Alphen aan den Rijn, The Netherlands) and quickly frozen in isopentane (2-Methylbutane, M32631, 
Sigma-Aldrich, Steinheim, Germany) at $-40{ }^{\circ} \mathrm{C}$. After an initial storage at $-70{ }^{\circ} \mathrm{C}, 16 \mu \mathrm{m}$ thick tissue sections were cut at $-15^{\circ} \mathrm{C}$ using a cryostat (CM3050S, Leica Microsystems GmbH, Nussloch, Germany) and mounted on silanized (3-(Triethoxysilyl)-propylamine, 8.21619.0100, Merck Millipore, Darmstadt, Germany) glass slides. Tissue used for immunohistochemistry was processed in two ways: Some samples were immersion-fixed in Bouin Hollande fixative, then extensively washed in 70\% isopropanol (9866.4, Carl Roth GmbH + Co. KG, Karlsruhe, Germany), dehydrated, and embedded in paraffin (Tissue-Tek Paraffin Wax, 4523, Sakura Finetek) (Schütz et al. 2008). Paraffin blocks were cut with a microtome (Microm HM 325, Thermo Scientific, Schwerte, Germany) and $7 \mu \mathrm{m}$ thick sections were mounted on silanized microscope glass slides. Alternatively, tissues were fixed in $4 \%$ buffered (pH 7.4) paraformaldehyde (P6148, Sigma-Aldrich), cryo-protected with $20 \%$ sucrose (9097, Carl Roth), frozen in isopentane, and $16 \mu \mathrm{m}$ sections cut with a cryostat.

\section{In situ hybridization}

Tissue sections on glass slides were air-dried at room temperature for $30 \mathrm{~min}$ and subjected to the following procedure (all procedures at room temperature unless otherwise stated): $1 \mathrm{~h}$ fixation in freshly prepared $4 \%(\mathrm{w} / \mathrm{v})$ paraformaldehyde (P6148, Sigma-Aldrich) in phosphate-buffered saline (PBS, pH 7.5 (10 X: $77 \mathrm{mM} \mathrm{Na}{ }_{2} \mathrm{HPO}_{4}$ (N350.1, Carl Roth), $23 \mathrm{mM} \mathrm{NaH}{ }_{2} \mathrm{PO}_{4}$ (K300.1, Carl Roth), 1,53 M $\mathrm{NaCl}$ (146994.1214, AppliChem, Darmstadt, Germany)), three times 10 min each washing in PBS, permeabilization for $10 \mathrm{~min}$ in $0.4 \%(\mathrm{v} / \mathrm{v})$ Triton X100 (3051.3, Carl Roth) in PBS. After additional washes in PBS, the sections were acetylated for $10 \mathrm{~min}$ with triethanolamine (T58300, Sigma-Aldrich)/acetic anhydride (320102, Sigma-Aldrich), washed again, dehydrated in 50\% and 70\% isopropanol, and finally air-dried. Complementary RNA probes for the detection of mouse Vil and Avil transcripts in tissue sections were generated from mouse C57BL/6 ileum cDNA. For Vil, a 788 nt long DNA fragment (GeneBank acc. no. NM_009509.2, nt 1521-2318) was amplified by PCR, and subcloned into pGEM-T (pGEM-T Vector System, A3600, Promega, Mannheim, Germany). For Avil, a 891 nt long DNA fragment (GeneBank acc. no. NM_009635.3, nt 1804-2694) was amplified by PCR, and subcloned into pGEM-T. For the detection of Egfp transcripts, a $601 \mathrm{bp}$ fragment from the EGFP coding sequence (pEGFP-N1, Clontech, Palo Alto, USA) was used (Schütz et al. 2015). The identity of the cloned gene fragments was confirmed by double-stranded sequencing (Microsynth Seqlab GmbH, Göttingen, Germany). Antisense and sense riboprobes were generated by in vitro transcription using T7 (T7 RNA Polymerase, R0884, Sigma-Aldrich) and SP6 polymerase (SP6
RNA Polymerase, 11487671001, Roche Diagnostics, Mannheim, Germany), respectively, and radioactive (UTP $\alpha$ S, [35S], NEG039C001MC, PerkinElmer, Waltham, USA), or non-radioactive (digoxygenin-11-UTP, DIG RNA Labeling Mix, 11277073910, Roche Diagnostics)-labeled nucleotides. The ISH procedure was essentially performed as described previously (Schütz et al. 2015), with a few modifications. The tissue sections on microscopic slides were covered with $30-40 \mu \mathrm{l}$ of hybridization solution, containing $50 \%$ formamide (24311.291, VWR International S.A.S, Briare, France), $0.6 \mathrm{M} \mathrm{NaCl}$ (146994.1214, AppliChem), $10 \mathrm{mM}$ Tris/HCl (pH 7.4) (Tris-HCL, 9090.3, and Tris-Base, 4855.2, Carl Roth), 1 mM Na 2 EDTA (8043.2, Carl Roth), 1 X Denhardt's (Denhardt's Solution, D9905, Sigma-Aldrich), $10 \%$ dextran sulfate (dextran sulfate sodium salt from Leuconostoc spp., 31395, Sigma-Aldrich), $100 \mu \mathrm{g} / \mathrm{ml}$ sonicated salmon sperm DNA (sonicated salmon sperm DNA, 201190, Agilent, Santa Clara, USA), 0.05\% (w/v) E. coli MRE600 tRNA (10109550001, Sigma-Aldrich), $20 \mathrm{mM}$ dithiothrei-

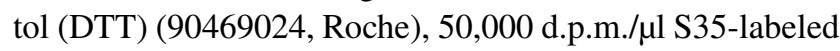
riboprobe, $2 \mathrm{ng} / \mu$ l digoxygenin-labeled riboprobe (when performing double-probe experiments), and cover-slipped. Hybridization was carried out overnight at $60^{\circ} \mathrm{C}$ in a humid chamber (Nunc Square BioAssay Dishes, 240835, Thermo Scientific). After hybridization, coverslips were removed in $2 \mathrm{X}$ standard saline/sodium citrate (SSC) $(20 \mathrm{X}: 3 \mathrm{M} \mathrm{NaCl}$ (146994.1214, AppliChem), 0,3 $\mathrm{M} \mathrm{Na}_{3}$ citrate $\times 2 \mathrm{H} 2 \mathrm{O}$ (3580.1, Carl Roth), $5 \mathrm{M} \mathrm{HCl}$ (9277.1, Carl Roth)) and the sections washed in the following order: $15 \mathrm{~min}$ in $2 \mathrm{X} \mathrm{SSC}$, $15 \mathrm{~min}$ in $1 \mathrm{X} \mathrm{SSC}, 30 \mathrm{~min}$ at $37{ }^{\circ} \mathrm{C}$ in RNase solution $(20 \mu \mathrm{g} / \mathrm{ml}$ RNase A (A3832.0500, AppliChem) and $1 \mathrm{U} / \mathrm{ml}$ RNase T1 (10109193001, Roche)), $30 \mathrm{~min}$ at RT in RNasesolution, $15 \mathrm{~min}$ in $1 \mathrm{X} \mathrm{SSC}, 15 \mathrm{~min}$ in $0.5 \mathrm{X} \mathrm{SSC}, 15 \mathrm{~min}$ in $0.2 \mathrm{X} \mathrm{SSC}, 60 \mathrm{~min}$ at $60^{\circ} \mathrm{C}$ in $0.2 \mathrm{X} \mathrm{SSC}, 15 \mathrm{~min}$ in 0.2 $\mathrm{X}$ SSC, and finally $15 \mathrm{~min}$ in distilled water. The detection of digoxygenin-labeled $E g f p$ probes was performed with alkaline phosphatase (AP)-conjugated anti-digoxygenin antibodies (11093274910, Anti-digoxigenin-AP, Fab fragments, Roche) diluted to $1.5 \mathrm{U} / \mathrm{ml}$, and $0.2 \mathrm{mM}$ BCIP (5-Bromo-4chloro-3-indolyl phosphate, 4-toluidine salt, 11383221001, Roche) and NBT (4-nitro blue tetrazolium chloride solution, 11383213001, Roche) using the manufacturers protocol, which yielded a purple-blue precipitate after 4-6 h. For the visualization of radioactive hybridization signals, sections were exposed to Carestream BIOMAX MR autoradiography film (Z358460-50EA, Sigma-Aldrich) for 2-3 days to estimate further exposure times, then coated under absence of light with nuclear emulsion (Ilford K5, 1355136, Harman Tech., Mobberley, UK), exposed for 2 weeks at $4{ }^{\circ} \mathrm{C}$ in the dark and finally developed using Ilford Phenisol developer (1757635, Harman) and Ilford Hypam fixer (1758285, Harman). Sections were counterstained with methyl green (323829, Sigma-Aldrich), and cover-slipped. Antisense and 
sense RNA probes were run in parallel in the same experiment to ensure equivalent conditions. In each experiment, vallate papilla containing taste buds was used as positive control.

\section{Immunohistochemistry}

Single brightfield IHC was performed as described previously (Schütz et al. 2015). All procedures were done at room temperature unless otherwise stated. Paraffinembedded tissue sections were deparaffinized in xylene (4436.2, Carl Roth) and rehydrated through a graded series of isopropanol (6752.5, Carl Roth), including $30 \mathrm{~min}$ incubation in methanol/0.3\% $\mathrm{H}_{2} \mathrm{O}_{2}$ (methanol, 4627.5, Carl Roth; hydrogen peroxide 30\%, 8070.2, Carl Roth) to block endogenous peroxidase activity. Subsequently, antigen retrieval was achieved by incubation in $10 \mathrm{mM}$ sodium citrate buffer $(0.1 \mathrm{M}$ citric acid monohydrate, 1.00244.1000, Merck Millipore; 0.1 M tri-sodium citrate dihydrate, 3580.3, Carl Roth; $\mathrm{pH} 6.0$ ) at $92-95{ }^{\circ} \mathrm{C}$ for $10 \mathrm{~min}$. Frozen sections were thawed and dried at $42{ }^{\circ} \mathrm{C}$ for $45 \mathrm{~min}$. For permeabilization, the sections were incubated for 10 min in $0.4 \%$ Triton X100 (3051.3, Carl Roth) followed by a 30 min incubation in $0.3 \% \mathrm{H}_{2} \mathrm{O}_{2}(80,702$, Carl Roth) to block endogenous peroxidase activity.

Non-specific binding sites were blocked with $5 \%$ bovine serum albumin (BSA) (albumin Fraction V, 8076.3, Carl Roth) in $50 \mathrm{mM}$ PBS for $30 \mathrm{~min}$, followed by an avidin-biotin blocking step (Avidin-Biotin Blocking Kit, SP-2001, Vector Laboratories, Burlingame, USA) for $20 \mathrm{~min}$ each. Primary antibodies included: rabbit anti-human advillin (ABIN4278537, antibodies-online.de, Aachen, Germany; 1:200 final dilution), mouse anti-human villin (sc-365310, Santa Cruz Biotech. Inc., Heidelberg, Germany; 1:200), chicken anti-EGFP (NB100-1614, Bio-Techne GmbH, Wiesbaden, Germany; 1:5,000). Primary antibodies were applied in PBS $/ 1 \%$ BSA over night at $16{ }^{\circ} \mathrm{C}$ followed by $2 \mathrm{~h}$ at $37^{\circ} \mathrm{C}$. After $3 \times 5$ min washes in double-distilled water and $10 \mathrm{~min}$ in PBS, the sections were incubated for $45 \mathrm{~min}$ at $37{ }^{\circ} \mathrm{C}$ with species-specific biotinylated secondary antibodies (biotin-SP AffiniPure donkey anti-rabbit IgG $(\mathrm{H}+\mathrm{L})$, 711-065-152; biotin-SP AffiniPure donkey anti-mouse IgG $(\mathrm{H}+\mathrm{L}), 715-065-151$; biotin-SP AffiniPure donkey antichicken $\operatorname{IgY}(\mathrm{IgG})(\mathrm{H}+\mathrm{L})$, 703-065-155; all from Jackson ImmunoResearch, Ely, UK), diluted 1:200 in PBS/1\% BSA, washed, and incubated for $30 \mathrm{~min}$ with avidin-biotin-peroxidase complex (Vectastain Elite ABC kit; PK-6100, Vector Laboratories, Burlingame, USA). Immunoreactions were then visualized by $8 \mathrm{~min}$ incubation in $100 \mathrm{mg} / 16 \mathrm{ml}$ DAB (3,3'-diaminobenzidine tetrahydrochloride hydrate, D5637, Sigma-Aldrich), enhanced by the addition of $600 \mathrm{mg} / 8 \mathrm{ml}$ ammonium nickel (II) sulfate hexahydrate (098825, SigmaAldrich). After three $5 \mathrm{~min}$ washes in distilled water, sections were counterstained with hemalaun solution (Hämatoxylin cryst., 104302, Merck Millipore), dehydrated through a graded series of isopropanol, cleared in xylene and finally mounted under coverslips. Digital brightfield pictures were taken with an Olympus AX70 microscope (Olympus Optical, Hamburg, Germany), equipped with an Olympus UC90 camera and Olympus cellSens analyses software.

For double brightfield IHC with two primary antibodies from the same donor species, i.e. rabbit anti-human advillin and rabbit-anti-human Doublecortin-like kinase 1 (DCLK1, AP7219b, Abgent, San Diego, CA, USA; 1:100), sections were sequentially stained in the following way: staining with the anti-advillin antiserum was done as described above, using DAB with nickel enhancement, which resulted in dark blue/black reaction product. After dehydration and again rehydration, staining with the anti-DCLK1 antiserum was visualized with DAB without addition of nickel, which resulted in a brownish staining. Advillin/DCLK1 co-immunoreactive cells thus should display both colors, although mostly in separate intracellular compartments, while additional single DCLK1-immunoreactive cells should stain brownish only.

Double immunofluorescence analysis was performed on paraffin sections as follows: After deparaffinization and blocking procedures (see above), anti-EGFP (1:500 final dilution) and anti-advillin (1:20) were co-applied in $\mathrm{PBS} / 1 \% \mathrm{BSA}$ and incubated over night at $16{ }^{\circ} \mathrm{C}$, followed by $2 \mathrm{~h}$ at $37^{\circ} \mathrm{C}$. After extensive washing in distilled water followed by PBS, immunoreactions for AVIL were visualized with a $\mathrm{Cy}^{\mathrm{TM}} 3$ AffiniPure donkey anti-rabbit $\operatorname{IgG}(\mathrm{H}+\mathrm{L})$ antibody (711-165-152; 1:100, Jackson ImmunoResearch). EGFP immunoreactions were visualized by a two-step procedure using a biotin-SP AffiniPure donkey anti-chicken IgY $(\mathrm{H}+\mathrm{L})$ secondary antibody (703-065-155, 1:200, Jackson ImmunoResearch), followed by streptavidin, Alexa Fluor ${ }^{\mathrm{TM}}$ 488 conjugate (S11223, 1:200, Invitrogen). Incubation times were 45 min with the biotinylated secondary antibody only, followed by $2 \mathrm{~h}$ incubation with a mixture of fluorochromeconjugated secondary antibody and streptavidin. Immunofluorescence signals were documented with a Zeiss Imager M2 microscope (Zeiss, Oberkochen, Germany), equipped with a Zeiss AxioCam HRc camera, and ZEN 2011 software. Co-expression ratios of two labels were determined by visual examination of 4-6 tissue sections each derived from 3 mice.

Double immunofluorescence analysis of Avil-Cre:mT/ $\mathrm{mG}$ mice was performed on cryosections as follows: After equilibration of the dried sections in PBS, they were permeabilized by incubation for $10 \mathrm{~min}$ in $0.4 \%$ Triton X100. After brief washes in PBS and distilled water, the sections were submerged for $3 \mathrm{~min}$ in methanol. This step eliminated the reporter mouse-intrinsic green (EGFP) and red (tdTomato) fluorescence and allowed the immunofluorescent 
visualization of two antigens. The subsequent staining procedure was performed as described above, using anti-EGFP (1:500) and anti-DCLK1 (1:20) antisera. Co-expression ratios of EGFP and DCLK1 were determined by visual examination of tissue sections derived from 4 mice.

\section{Results}

\section{Villin and advillin expression patterns in taste cells and in sensory neurons}

For an unambiguous detection of Vil and Avil mRNA on a cellular level in tissue sections, we designed riboprobes for ISH experiments, and tested these tools on sections containing oral taste buds. Both Vil (Fig. 1a) and Avil (Fig. 1b)
Fig. 1 Villin and advillin expression patterns in mouse taste buds and in dorsal root ganglia. Vil mRNA (a), and Avil mRNA (b), where both detected with antisense (as) riboprobes in radioactive ISH in taste buds of the mouse vallate papilla. The use of sense (s) riboprobes for Vil (c) and Avil (d) did not result in specific staining. Villin-immunoreactivity outlined many, if not all taste cells, with the apical tip showing the most intense staining (e). Likewise, advillin-immunoreactive cells were present in taste buds, sometimes showing intense intra-cellular staining (f). Absence of villin-immunoreactivity (g), and presence of advillin-immunoreactivity (h) in dorsal root ganglion neurons. Sections from ISH were counter-stained with methyl green, sections from IHC with hemalaun. The bar in a represents $50 \mu \mathrm{m}$ and applies to $\mathbf{a}-\mathbf{d}$. The bar in e represents $20 \mu \mathrm{m}$ and also applies to $\mathbf{f}$. The bar in $\mathbf{g}$ represents $20 \mu \mathrm{m}$ and also applies to $\mathbf{h}$
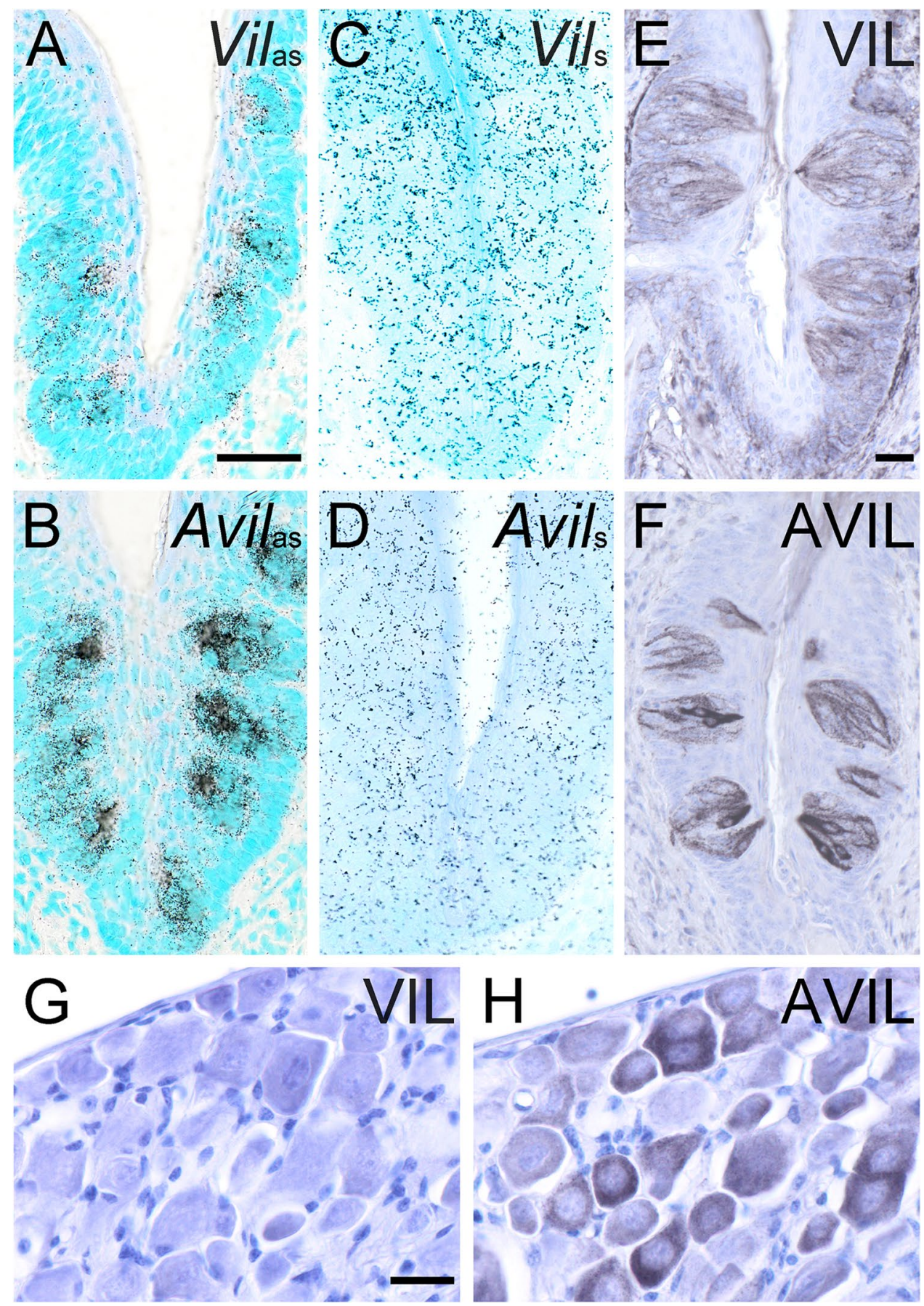
antisense riboprobes selectively labeled taste buds in the mouse vallate papilla, while their corresponding sense riboprobes did not result in specific staining (Fig. 1c, d). On the protein level, villin-immunoreactive taste cells were detected with a monoclonal mouse anti-human villin antibody (Fig. 1e). A similar staining pattern was obtained with a polyclonal rabbit anti-human advillin antiserum (Fig. 1f). Dorsal root ganglia harbor sensory neurons that are known to express Avil, but not Vil (Chuang et al. 2018). In our hand, the anti-villin antibodies did not show crossreactivity with mouse advillin, because they failed to label dorsal root ganglia neurons (Fig. 1g), while many neurons were stained with the anti-advillin antibodies (Fig. 1h). Likewise, the anti-advillin antibodies did not display villin cross- reactivity (see below, Figs. 3, 4). Taken together, specific and sensitive detection methods for both, Vil and Avil transcripts and their protein products on mouse tissue sections could be established.

\section{Villin and advillin expression patterns in the mouse gastro-intestinal tract}

The mouse stomach is divided into the non-glandular fundus and the glandular corpus, with the limiting ridge representing the anatomical border. At the so-called squamocolumnar junction, the stratified squamous epithelium of the fundus is replaced by a columnar arrangement of epithelial cells of the corpus. Here, clusters of tuft cells that express taste-cell characteristics (Eberle et al. 2013; Hass et al. 2007) are arranged in a palisade-like manner (Luciano and Reale 1992). Using ISH we found that both, Vil (Fig. 2a) and Avil (Fig. 2b) mRNAs were uniformly expressed in the entire surface epithelium and in the deeper glandular zone, showing no preference for individual cells. Avil signal intensities were found generally stronger than those for $\mathrm{Vil}$, and the corresponding sense riboprobes did not produce detectable signals (data not shown). On the protein level, villin- (Fig. 2c) and advillin- (Fig. 2d) immunoreactivities were most prominent at the apical tips of individual cells, but also labeled the
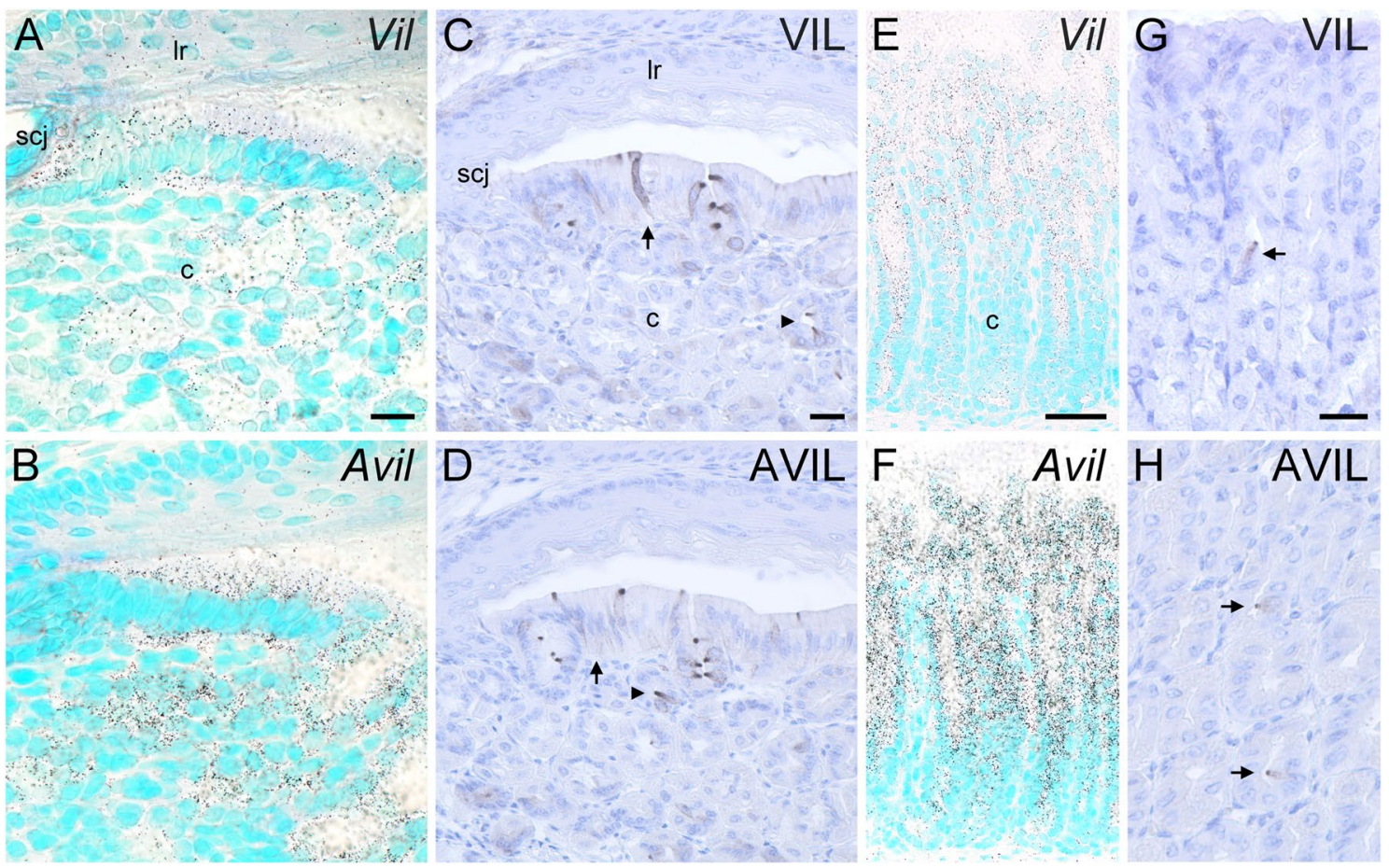

Fig. 2 Villin and advillin expression patterns in the mouse stomach. In the mouse stomach, the squamo-columnar junction (scj) represents the histological transition from the limiting ridge (lr) to the corpus (c). (a) Vil mRNA, detected by radioactive ISH, was present both in epithelial cells of the columnar aspect of the corpus, and in deeper glands. (b) Avil mRNA displayed a similar expression pattern, with no preference in staining intensity for individual cells. On the protein level, both villin- (c) and advillin- (d) immunoreactivities were confined to individual cells of the columnar epithelium (arrows) and in deeper glandular aspects (arrowheads). Especially the staining of the apical tips of the columnar and flask-shaped cells was most intense. Vil (e) and Avil (f) mRNA was present throughout the mucosal epithelium of the corpus, while immunoreactivity was confined to individual cells (arrows in $\mathbf{g}$ and $\mathbf{h}$ ). Sections from ISH were counterstained with methyl green, sections from IHC with hemalaun. The bar in $\mathbf{a}$ represents $20 \mu \mathrm{m}$ and also applies to $\mathbf{b}$. The bar in $\mathbf{c}$ represents $20 \mu \mathrm{m}$ and also applies to $\mathbf{d}$. The bar in e represents $50 \mu \mathrm{m}$ and also applies to $\mathbf{f}$. The bar in $\mathbf{g}$ represents $20 \mu \mathrm{m}$ and also applies to $\mathbf{h}$ 


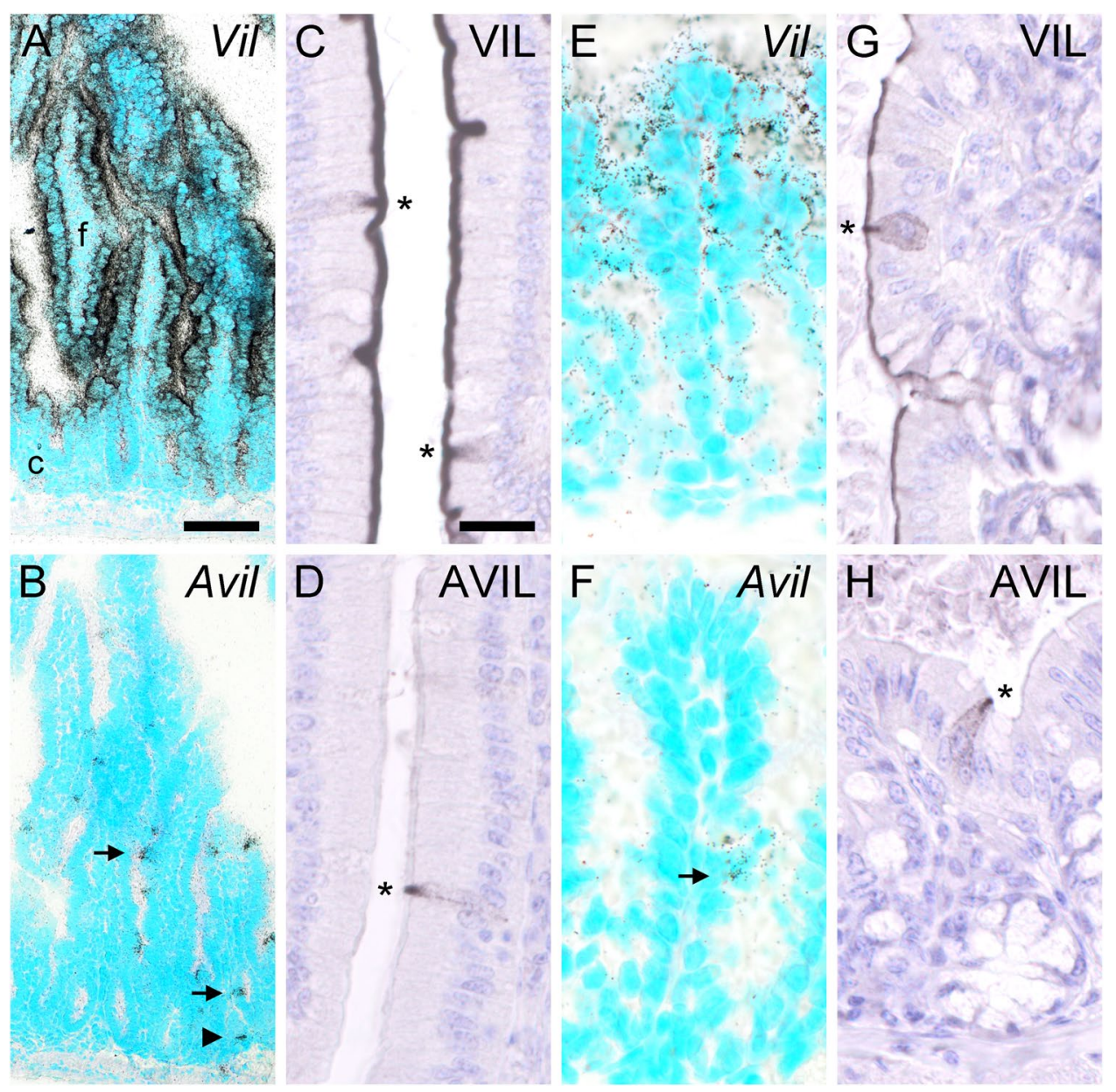

Fig. 3 Villin and advillin expression patterns in the mouse small and large intestine. (a) Vil mRNA, detected with antisense riboprobes in radioactive ISH, was present in the entire epithelial lining of the small intestine, shown here for duodenum. Note much stronger expression in folds (f) compared to crypts (c). (b) Avil mRNA was confined to individual epithelial cells, both in folds (arrow) and in crypts (arrowhead). (c) Villin-immunoreactivity was seen along the entire apical aspects of the duodenal mucosa, occasionally with additional cell body labeling (asterisks). (d) Advillin-immunoreactivity was confined to individual cells in the mucosal epithelium. Note prominent staining of the apical tip (asterisk). (e) In the large intes-

columnar and flask-shaped cells throughout in a punctate fashion. In all other parts of the corpus, down to the transition between the pylorus and the duodenum, Vil (Fig. 2e) and Avil (Fig. 2f) mRNAs likewise were uniformly present in the whole surface epithelium, with signal intensities diminishing in deeper glandular aspects. Again, immunoreactivities for villin (Fig. 2g) and advillin (Fig. 2h) were restricted to individual cells. Taken together, on the mRNA level both Vil and Avil genes were found to be expressed by seemingly all epithelial cells of the glandular stomach, while detectable protein levels were confined to individual cells when using IHC. tine, Vil mRNA was mainly present in the upper half of the crypts, shown here for the colon. (f) Again, presence of Avil mRNA was confined to individual cells. (g) Villin-immunoreactivity was seen along the entire apical aspects of the colonic mucosa, occasionally with additional cell body labeling (asterisk). (h) Advillin-immunoreactivity was confined to individual cells in the mucosal epithelium (asterisk). Sections from ISH were counter-stained with methyl green, sections from IHC with hemalaun. The bar in a represents $100 \mu \mathrm{m}$ and also applies to $\mathbf{b}$. The bar in $\mathbf{c}$ represents $20 \mu \mathrm{m}$ and also applies to $\mathbf{d}-\mathbf{h}$

In the rodent small intestine, solitary tuft cells locate to crypts and folds of the single-layered mucosal epithelium and make up approx. 1-7\% of all epithelial cells, depending on the microbial status (Howitt et al. 2016). Strong Vil ISH signals were present on seemingly all epithelial cells lining the folds, but signals were weak to undetectable in crypts (Fig. 3a). ISH signals for Avil, on the other hand, were present on individual cells in both crypts and folds (Fig. 3b). Villin-immunoreactivity strongly labeled the apical brush border of the entire epithelium, with only goblet cells showing weaker staining (Fig. 3c). In some cells, strong immunoreactivity was also seen extending from the luminal side into the cell body, and the antibodies also labeled the whole 
Fig. 4 Villin and advillin expression patterns in the mouse gall bladder. (a) Vil mRNA was present in the entire epithelial lining of the gall bladder, showing no regional accumulations e.g. in neck or corpus. (b) higher magnification view from the boxed area in $\mathbf{a}$.

(c) Villin-immunoreactivity was prominent in the apical tips of individual cells in the gall bladder main epithelium (asterisk), and (d) in associated glands (asterisk). (e) Avil mRNA was detected in individual cells in all parts of the gall bladder. (f) Higher magnification view from the boxed area in e. Advillinimmunoreactivity also was seen in individual cells along the inner lining of the gall bladder, both in the main epithelium (g) and in glands (h). Sections from ISH were counter-stained with methyl green, sections from IHC with hemalaun. The bar in a represents $100 \mu \mathrm{m}$ and also applies to e. The bar in $\mathbf{b}$ represents $50 \mu \mathrm{m}$ and also applies to f. The bar in c represents $10 \mu \mathrm{m}$ and also applies to $\mathbf{d}$ and $\mathbf{h}$. The bar in $\mathbf{g}$ represents $20 \mu \mathrm{m}$. (Color figure online)

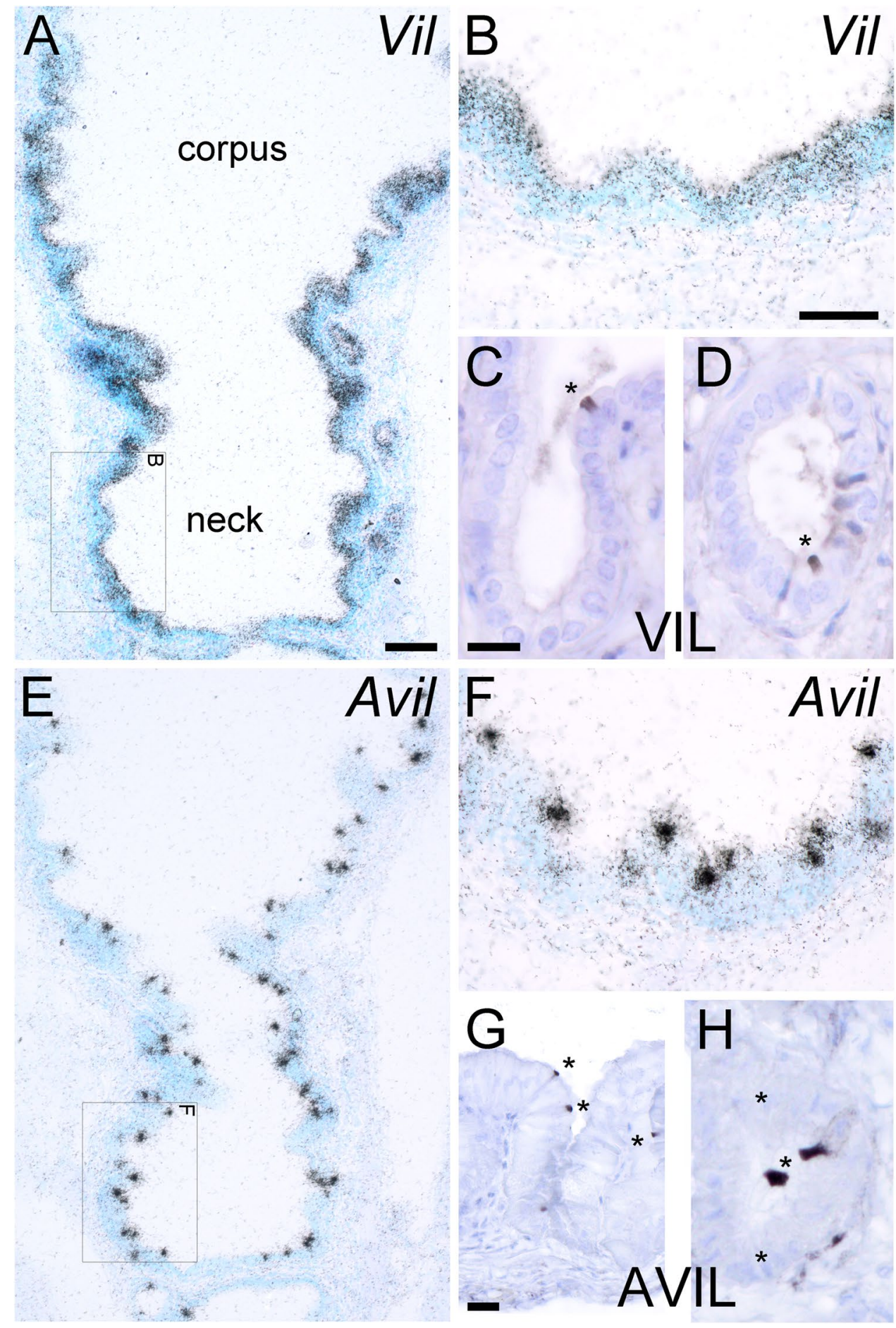

cell in a punctuate fashion. Advillin-immunoreactivity was confined to individual cells (Fig. 3d). Again, the apical tip showed the most intense labeling, while the rest of the cell displayed punctuate immunoreactivity.

The mucosa of the large intestine is characterized by the presence of straight crypts and the lack of villi. Moderate Vil ISH signals were most prominent in the upper half of the crypts and weak to absent in the lower half (Fig. 3e). Again, no preference for individual cells was observable. ISH signals representing Avil gene expression again were confined to solitary cells (Fig. 3f). In analogy to the small intestine, villin-immunoreactivity labeled the entire brush border and additionally some solitary cells (Fig. 3g). Advillin-immunoreactivity was found restricted to solitary 
cells, with staining characteristics similar to that found in the small intestine (Fig. 2h). Taken together, while villin was found expressed by almost all intestinal mucosal epithelial cells, advillin expression was found confined to individual cells, both on the mRNA and on the protein level, suggesting restricted expression in tuft cells.

\section{Villin and advillin epression patterns in the mouse gall bladder}

The mouse gall bladder and extrahepatic bile duct epithelia harbor high densities of tuft cells (Iseki 1991; Luciano and Reale 1969; Schütz et al. 2015). We found that Vil ISH labeled the entire epithelium of the gall bladder (Fig. 4a, b), while Avil mRNA was expressed by solitary cells (Fig. 4e, f). On the protein level, immunoreactivity for villin was detectable in the apical tips of individual cells (Fig. 4c, d), both in the main epithelium and in peribiliary glands. A similar staining pattern was observed with anti-advillin antibodies (Fig. 4g, h). Taken together, while villin was found expressed by almost all cholangiocytes and tuft cells of the gall bladder, advillin expression was found restricted to individual cells, both on the mRNA and on the protein level, suggesting selective presence in tuft cells.

\section{Advillin and villin co-expression patterns}

To investigate if advillin and villin are co-expressed in epithelial cells we performed double-ISH experiments. Nonradioactive labeling of Vil mRNA, in combination with radioactive labeling of Avil mRNA resulted in a fully overlapping pattern in vallate papilla taste buds (Fig. 5a). In the small intestine, exemplified here for the duodenum, solitary Avil signals co-localized with Vil signals in the mucosa (Fig. 5b).

\section{Advillin expression is confined to tuft cells}

Although tuft cells display region-specific heterogeneity in their molecular signatures (Nadjsombati et al. 2018), a core gene signature has emerged that includes expression of Chat (O'Leary et al. 2018; Schütz et al. 2015, 2019).
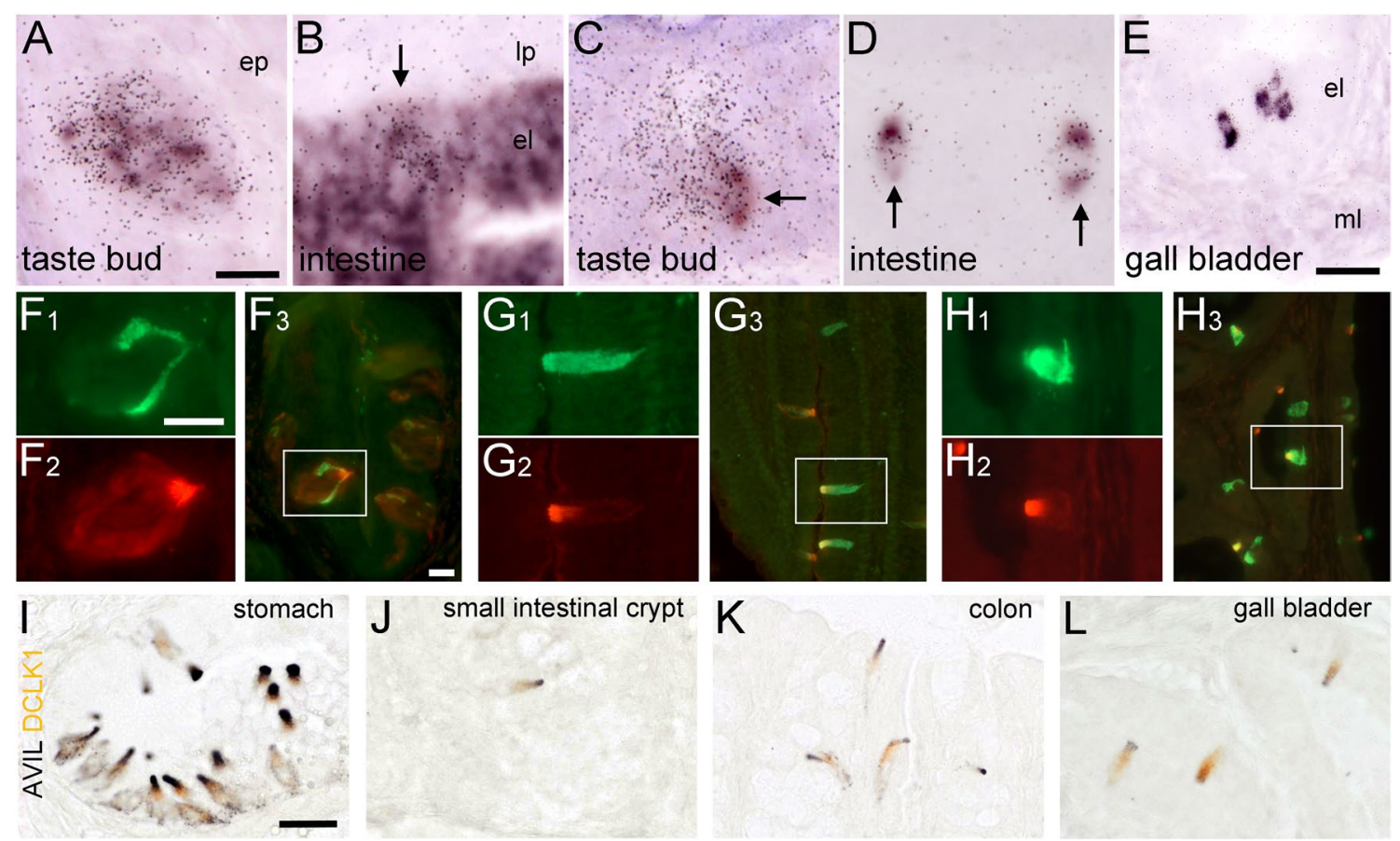

colon

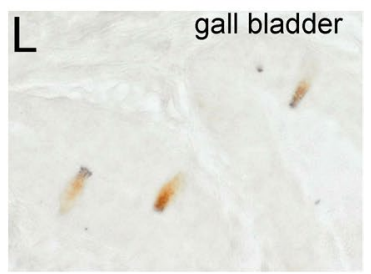

Fig. 5 Double-ISH and double-IHC experiments. Simultaneous detection of Vil (non-radioactive label) and Avil (radioactive label) mRNAs in a mouse taste bud (a), and in the duodenum (b). Note that Avil signals overlap with Vil (arrow in b). Simultaneous detection of Chat-Egfp (non-radioactive label) and Avil (radioactive label) mRNAs in a mouse taste bud (c), in the duodenum (d), and in the gall bladder (e). Note partial overlap in taste bud (arrow in c) and complete overlap of both labels in intestine (arrows) and in gall bladder. Double-IHC analysis of ChAT-EGFP (green label) with advillin (red label) in taste buds (f), in the duodenum (g), and in the gall bladder (h). The boxed area in the composite pictures $\mathrm{f} 3, \mathrm{~g} 3$, and $\mathrm{h} 3$ is pre- sented in magnification with the single label in $\mathrm{f1}, 2, \mathrm{~g} 1,2$, and $\mathrm{h} 1,2$. Double brightfield IHC analysis of advillin (black reaction product) with DCLK1 (brown reaction product) at the squamo-columnar junction of the stomach (i), in the small intestine (j), in the large intestine (k), and in the gall bladder (l). $\underline{e l}$ epithelial layer; $e p$ epidermis; $l p$ lamina propria; $m l$ muscle layer. The bar in a represents $20 \mu \mathrm{m}$ and also applies to $\mathbf{b}-\mathbf{d}$. The bar in e represents $25 \mu \mathrm{m}$. The bar in f1 represents $25 \mu \mathrm{m}$ and also applies to f2, g1, 2, h1, 2. The bar in f3 represents $20 \mu \mathrm{m}$ and also applies to $\mathbf{g} \mathbf{3}$ and $\mathbf{h 3}$. The bar in $\mathbf{i}$ represents $20 \mu \mathrm{m}$ and also applies to $\mathbf{j}-\mathbf{l}$. (Color figure online) 
To determine if the solitary intestinal and biliary cells expressing advillin message and protein were tuft cells, we utilized a transgenic reporter mouse line that expresses Egfp under the control of the ChAT promoter (Schütz et al. 2008; von Engelhardt et al. 2007), and performed doubleISH and -IHC experiments to simultaneously detect EGFP and advillin. In taste buds of the vallate papilla, Egfp expressing taste cells were visualized by the non-radioactive label (Fig. 5c). Signals representing Avil expression covered Egfp-expressing and non-expressing cells, indicative of Avil expression in both, type II (bitter, sweet, and umami taste) and III (sour and salty taste) taste cells. A similar staining pattern was seen with IHC (Fig. 5f). In the epithelium of the small intestine, Egfp and Avil expression almost fully overlapped (Fig. $5 \mathrm{~d}, n=3$ mice, $\geq 100$ cells analyzed). Only occasionally, epithelial cells displaying Avil, but not Egfp expression, were found in crypts (data not shown). Double-IHC revealed a $91.6 \pm 4.7 \%$ co-expression frequency along the gastro-intestinal tract $(83.3 \%$ in stomach, $n=66$ cells analyzed; $90.8 \%$ in duodenum, $n=736$ cells; $91.8 \%$ in jejunum, $n=256$ cells; $96.9 \%$ in ileum, $n=350$ cells; $95.2 \%$ in colon, $n=456$ cells). In the gall bladder, Egfp expressing tuft cells showed almost full co-expression of Avil ( $n \geq 100$ cells analyzed) in doubleISH experiments (Fig. 5e), and $88.6 \%$ co-expression frequency in double-IHC ( $n=184$ cells analyzed, Fig. $5 \mathrm{~h}$ ). All other non-co-expressing immunoreactive cells along the gastro-intestinal and biliary tracts had an advillin ${ }^{+} /$ EGFP $^{-}$phenotype. DCLK1 is another established tuft cell marker, and also present in rather immature tuft cells of intestinal crypts (Bjerknes et al. 2012; Gerbe et al. 2011). Co-staining for advillin and DCLK1 in brightfield IHC revealed a complete overlap at the limiting ridge of the stomach (Fig. 5i), in small intestinal crypts (Fig. 5j), large intestine (Fig. 5k), and gall bladder (Fig. 5l) (>100 cells analyzed per tissue), suggesting that, especially in the intestine, advillin is expressed during all stages of tuft cell maturation.

\section{Advillin expression pattern in the absence of tuft cells}

Gastro-intestinal tuft cells have been ascribed chemosensory, immunomodulating, and neuromodulating functions (O'Leary et al. 2018). However, it is still under debate if a single type of tuft cell exerts all these functions, or if several tuft cell lineages exist. Since not all cholinergic tuft cells co-expressed advillin in our double-labeling immunohistochemical experiments (see above), we asked whether the additional single-labeled advillin cells represented a different tuft cell type, e.g. non-chemosensory tuft cells, or even enteroendocrine cells (Sutherland et al. 2007). Thus, we analyzed by ISH tissue from Pou $2 \mathrm{f3}^{-/-}$mice that lack type II taste cells (Matsumoto et al. 2011) and chemosensory-type, TRPM5-positive tuft cells (Matsumoto et al. 2011; Yamashita et al. 2017). Avil mRNA was readily detected in the vallate papilla taste buds (Fig. 6a). In the stomach, almost all epithelial cells of the glandular stomach at the squamo-columnar junction (Fig. 6b) still gave Avil ISH signals. In the small intestine (exemplified here for duodenum), however, Avil ISH signals were completely absent from villi and crypts, while ISH signals were still detected in some neurons in the submucous and myenteric plexus (Fig. 6c). Avil ISH signals were also completely absent from the gall bladder epithelium (Fig. 6d). In comparison, advillin staining by IHC was faintly present in vallate papilla taste buds (Fig. 6e), but absent from all epithelial cells along the gastro-intestinal and biliary tract (Fig. 6f-h).

\section{Advillin promoter-driven expression of Cre-recombinase in tuft cells}

In our present study advillin was found to be a tuft cell-specific protein, especially in the mucosal epithelia of the intestine and gall bladder. Thus, we wanted to know if the Avil promoter could serve as a genetic tool to specifically target intestinal and biliary tuft cells. Hemizygous male Avil-Cre mice were mated with homozygous female $\mathrm{mT} / \mathrm{mG}$ mice. The doublefluorescent reporter mice carry a cDNA for a red fluorescent (tdTomato) protein that is flanked by loxP sites, followed by a polyadenylation sequence and the Egfp coding sequence. The tdTomato gene will be selectively removed in the presence of active Cre-expression, and instead the Egfp gene transcribed (Fig. 7a). In progeny from these matings, native EGFP fluorescence was detectable in taste cells of the vallate papilla (Fig. 7b), and in solitary epithelial cells of both, the intestine (Fig. 7c) and the gall bladder (Fig. 7d). Enhancing EGFP detection with anti-EGFP antibodies resulted in a strong labeling of cells in vallate papilla taste buds and innervating sensory nerve fibers (Fig. 7e). Single EGFP-immunoreactive cells lined the columnar epithelium at the gastric groove and were also present in the glandular stomach (Fig. 7f). In the intestine, solitary EGFP-immunoreactive epithelial cells were detected in villi and crypts, in addition to a few presumably sensory nerve fibers coursing through the muscle layers (Fig. 7g). Gastro-intestinal nerve cell bodies were devoid of detectable EGFP expression (inset in Fig. 7g). Finally, many EGFP-immunoreactive cells lined the epithelium of the gall bladder (Fig. 7h). Double immunofluorescence with EGFP and advillin antibodies (Fig. 7i-k) revealed that recombination events had been obtained in true advillin expressing tuft cells. To obtain information about the targeting-efficiency of the Avil-Cre promoter we determined the EGFP/DCLK1 co-expression pattern in these mice. At the limiting ridge of 
Fig. 6 Advillin expression pattern in Pou $23^{-/-}$mice. Avil mRNA, detected with antisense riboprobes in radioactive ISH, was present in vallate papilla taste buds (a), and in the epithelium of the glandular stomach (b) of Pou $2 \mathrm{f}^{-1-}$ mice. Avil mRNA was absent from intestinal crypts and villi, but present in some neurons of the submucous (arrowhead) and myenteric (doubled arrowhead) plexus (c). Avil mRNA was absent from the gall bladder epithelium (d). Using IHC, advillin-immunoreactivity was detected faintly in taste buds (e, arrow), but was absent from the epithelium of stomach (f), duodenum (g), and gall bladder (h). Sections from ISH were counter-stained with methyl green, sections from IHC with hemalaun. $c$ crypt; $e l$ epithelial layer; $e p$ epidermis; $l r$ limiting ridge; $\mathrm{ml}$, muscle layer; $v$ villus. The bars in $\mathbf{a}$ and $\mathbf{b}$ represent $100 \mu \mathrm{m}$. The bars in $\mathbf{c}$ and $\mathbf{d}$ represent $50 \mu \mathrm{m}$. The bar in e represents $20 \mu \mathrm{m}$ and also applies to $\mathbf{f}-\mathbf{h}$. (Color figure online)

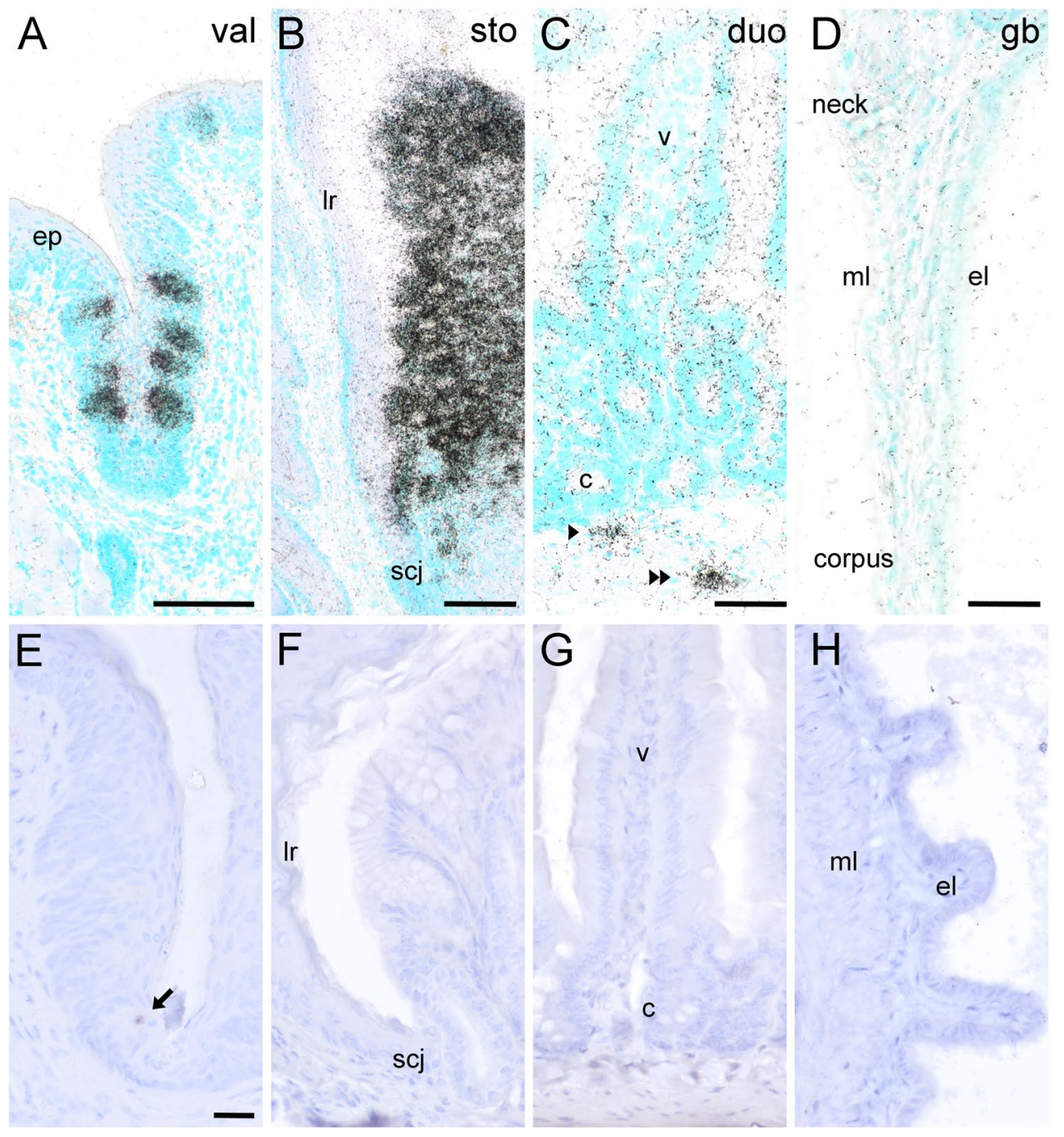

the stomach, $58.6 \pm 28.7 \%$ of the DCLK1-immunoreactive tuft cells were traced. In duodenum $(15.6 \pm 5.5 \%)$, jejunum $(12.2 \pm 5.3 \%)$, ileum $(18.0 \pm 6.2 \%)$, and colon $(33.4 \pm 8.6 \%)$ low targeting frequencies were obtained. Finally, in the gall bladder $99.0 \pm 1.8 \%$ of the DCLK1 tuft cells were also EGFPpositive. These data are proving a tissue- and region-dependent applicability of Avil-Cre mice to genetically target gastro-intestinal and biliary tuft cells.

\section{Discussion}

The introduction of villin-antibodies as tuft cell marker in immunohistochemical analysis dates back almost 30 years (Höfer and Drenckhahn 1992). In mice, a comparison of the transcriptional profiles of small intestinal TRPM5-positive tuft cells with that of other enterocytes revealed that villin was expressed equally strong in both cell populations, while advillin expression was restricted to tuft cells (Bezençon et al. 2008). To be sure that our immunohistochemical tools had an adequate specificity, we stained sections containing taste cells, which express both, villin and advillin, and dorsal root ganglia that are known to express advillin but not villin (Chuang et al. 2018). We found similar staining patterns for villin and advillin in taste cells, however many dorsal root ganglia neurons stained for advillin, but not for villin, thus ruling out advillin cross-reactivity of the anti-villin antibody. Importantly, the anti-advillin antibody we used in our study did not stain the entire intestinal surface epithelium, as seen with anti-villin antibodies, which further validated their specificity. Hence, both immunohistochemical tools we employed showed an appropriate selectivity in detecting their cognate proteins.

We here documented the advillin expression pattern in the mouse alimentary tract on a cellular histological level. The major finding of our study is that advillin, unlike villin, displays a tuft cell-restricted expression pattern in the intestinal and biliary tract mucosal epithelia, both on the mRNA and protein levels. In addition, we found that advillin expression on the protein level was completely absent from the 

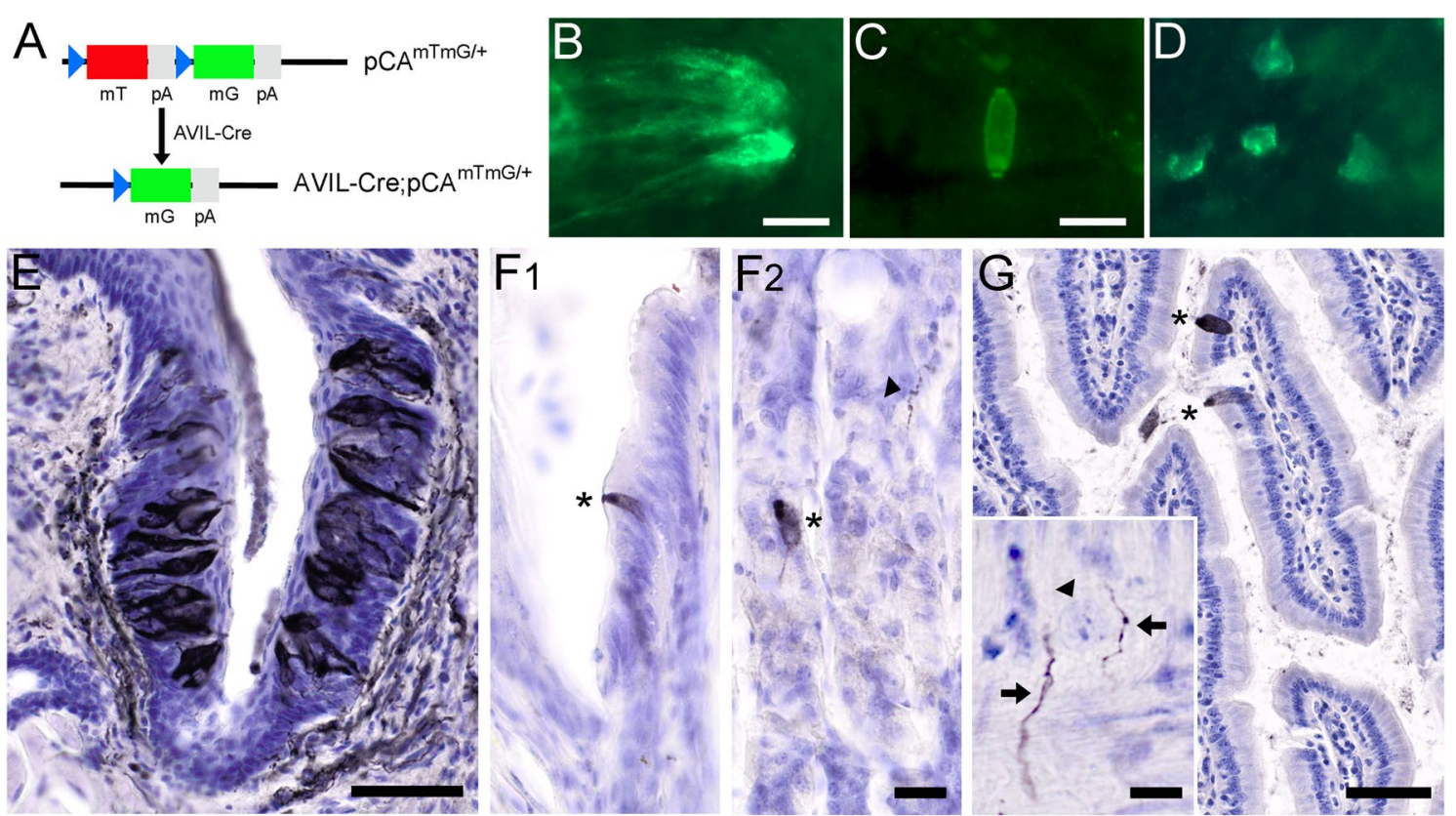

$F_{1}$
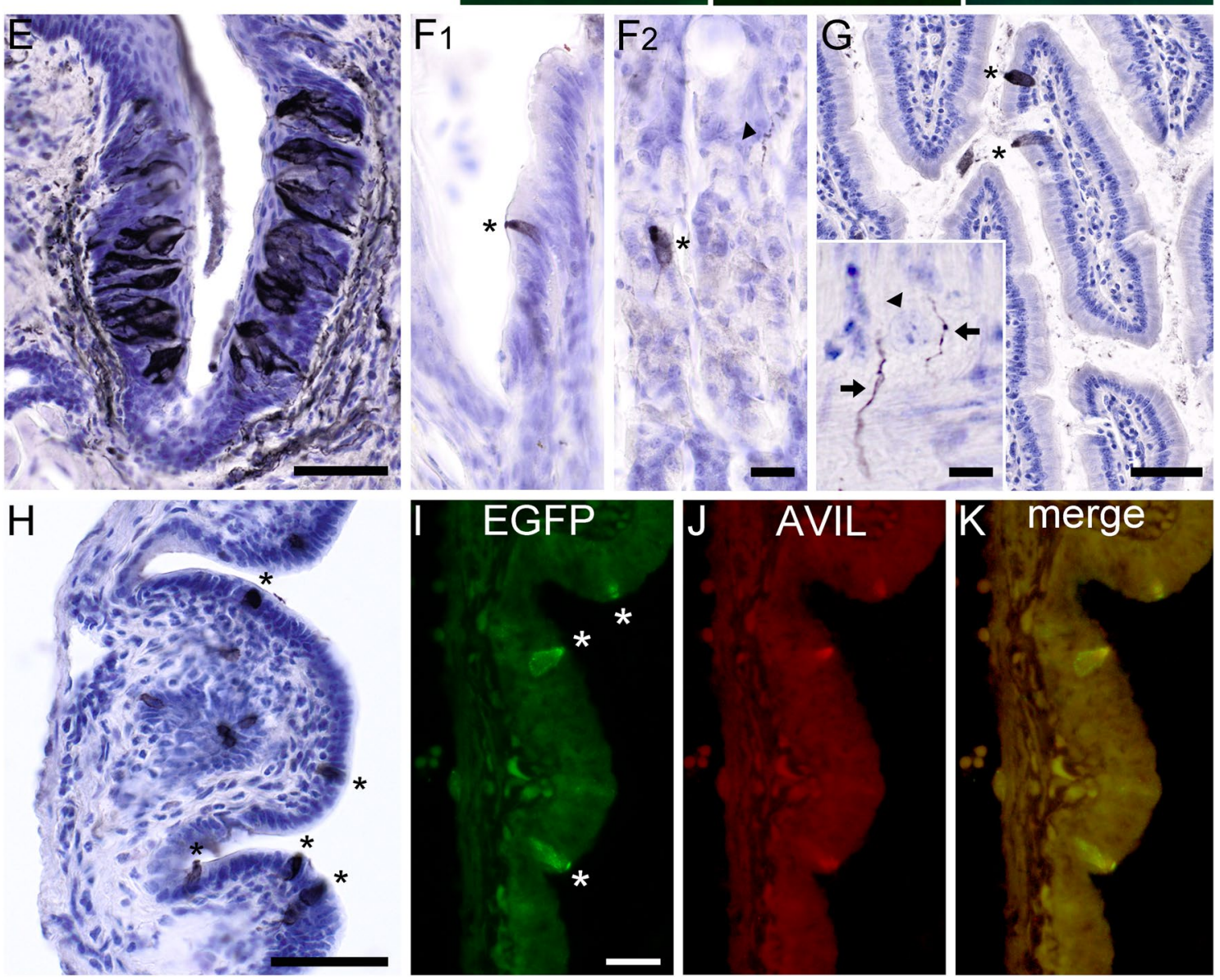

Fig. 7 Avil-Cre mice are a tool to genetically target tuft cells in the mouse alimentary tract. The mating of mice that harbor the double fluorescent reporter, $\mathrm{mT} / \mathrm{mG}$, with a mouse line that expressed Crerecombinase under the control of the advillin promoter (Avil-Cre) resulted in cell-specific excision of $m T$ due to flanking loxP (blue triangle) sites, and activation of Egfp expression (a). pA = polyadenylation site. Native EGFP fluorescence in fresh tissue representing Cre activity in vallate papilla (b), duodenal mucosa (c), and gall bladder (d). Enhancing EGFP detection with antibodies revealed presence of EGFP in vallate papilla taste buds, and in innervating presumably sensory nerve fibers (e). Similarly, EGFP was present in solitary cells at the limiting ridge (f1, marked by asterisk) and in the glandular

gastro-intestinal and biliary tract mucosa of Pou $f 3^{-/-}$mice, while expression was still present in oral taste cells, and on the mRNA level in stomach. This suggests that advillin is also expressed in type III taste cells that detect sour and salty taste modalities, and that extra-oral expression is confined to the chemosensory tuft cell lineage, and to sensory neurons. In our double-labeling immunohistochemical experiments we observed that about $10 \%$ of the advillin-immunoreactive corpus of the stomach (f2, marked by asterisk), and in nerve fibers (arrowhead in f2) traveling bottom-up in these glands. In the duodenum, solitary cells in the mucosal epithelium were labeled (asterisks) in addition to presumably sensory nerve fibers in the muscle layers (arrows in inset), while nerve cell bodies were not stained (arrowhead in inset) (g). EGFP-positive cells were present in the epithelium of the gall bladder (asterisks) (h). Double-immunofluorescence analysis of EGFP (i, green label) and advillin (k, red label) showed co-existence $(\mathbf{k})$ in the duodenum. The bar in $\mathbf{b}$ represents $10 \mu \mathrm{m}$ and also applies to $\mathbf{d}$. The bar in $\mathbf{c}$ represents $20 \mu \mathrm{m}$. The bars in e, $\mathbf{g}$ (inset $10 \mu \mathrm{m})$, and $\mathbf{h}$ represent $50 \mu \mathrm{m}$. The bar in f represents $20 \mu \mathrm{m}$. The bar in $\mathbf{i}$ represents $20 \mu \mathrm{m}$ and also applies to j, k. (Color figure online)

cells did not co-express EGFP driven by the Chat promoter. On the other hand, a completely overlapping expression pattern was seen with another tuft cell marker, DCLK1. This suggests that advillin is expressed early on in the tuft cell lineage, while the cholinergic phenotype of these cells may be established at a more later time point of cell maturation. Hence, we propose that advillin should be added as a morphology marker to the tuft cell minimal gene signature, 
which already includes POU2F3, IL-25, COX1 and COX2, ALOX5, TRPM5, and ChAT (reviewed by O'Leary et al. 2018). Our actual findings in mice are underscored by our recent analysis of the distribution pattern and molecular signature of cholinergic tuft cells in the normal human alimentary tract. There, presence of advillin-immunoreactivity was also confined to ChAT-positive tuft cells in the small and large intestine, in peribiliary glands, and in small intra- and interlobular pancreatic ducts (Schütz et al. 2019).

A discrepancy between the tissue distribution pattern of mRNA versus protein was observed for advillin in the stomach. Messages were present in seemingly all epithelial cells, even in Pou $2 \mathrm{f}^{-/-}$mice, while detectable protein expression was confined to solitary tuft cells in immunohistochemical analysis. First, this could mean that all epithelial cells in the stomach produce advillin, with non-tuft cells expressing this protein at levels that are below the detection limit in immunohistochemical experiments. Second, lack of protein detection in all but tuft cells may result from a post-transcriptional silencing mechanism. Third, a cross-reactivity of our Avil-mRNA ISH probe with another expressed gene may occur in this organ. Although the definite reason for the observed discrepancy remains enigmatic, our finding of a restriction of Avil-promoter-driven Cre recombinase activity to solitary cholinergic tuft cells in the entire gastro-intestinal and biliary tract strongly suggests that functionally relevant Avil gene expression and advillin quantities are only found in tuft cells. A similar discrepancy between the presence of mRNA and protein was observed for villin in stomach and biliary tract, while detection completely matched in the intestine. Again, functionally relevant protein amounts may differ along the aspects of the alimentary and biliary tracts.

Originally, advillin expression was considered to be largely restricted to sensory neurons (Chuang et al. 2018). We were able to show by IHC that advillin was present in sensory neurons of dorsal root ganglia, while villin was not. Advillin mRNA was also detected by us in neurons of the intestinal submucosal and myenteric plexus. This would be in agreement with a recent report stating that advillin is present in all neurons of the autonomic nervous system (Hunter et al. 2018). However, gut-intrinsic neurons never stained positive in our own IHC using anti-advillin antibodies, nor did they display EGFP-immunoreactivity in our analysis of an Avil-Cre:mT/mG double transgenic mouse line. Instead, presumably sensory nerves were prominent around taste buds in vallate papillae, in the muscle layers of the intestine, and in the glandular stomach of Avil-Cre:mT/mG mice. This indicates that Avil-promoter driven Cre expression and activity is not established in gut autonomic plexus neurons in the Avil-Cre mouse line we used. Recent support comes from our targeting of tracheal brush cells, where a conditional elimination of brush cell-derived $\mathrm{ACh}$, but not neuronal ACh, was obtained by crossing the Avil-Cre mouse line with mice that harbor a floxed ChAT allele (Misgeld et al. 2002). Trachea preparations from these mice still retained neural cholinergic signaling, i.e. intact cholinergic constriction evoked by electrical field stimulation. The effect of a formylated bacterial peptide on stimulating particle transport speed, however, was almost fully lost (Perniss et al. 2020).

Tuft cell biology has recently received tremendous attention since the discovery that they may function as chemosensory sentinels that monitor intestinal, respiratory, and urethral infection, and that they initiate adequate protective responses through activation of type 2 immunity (recently reviewed by von Moltke and Pepper 2018). Hence, deciphering the specific roles of individual tuft cell components, i.e. receptors and signaling molecules, in these scenarios is warranted to understand in detail how these cells do their job in a given surrounding and pathophysiological situation. Uncovering the multiple functions tuft cell components play can be achieved by tuft cell-specific manipulation of gene expression. Along this line, multiple transgenic mouse tools have been implemented, that are more or less tuft cellspecific. Currently available mouse lines that express Crerecombinase in tuft cells are driven by Pou2f3 (McGinty et al. 2020), Trpm5 (Kusumakshi et al. 2015), Dclk1, Vil, Chat, Tas2r131, or Tas2r143 promoters (recently summarized by O'Leary et al. 2018). Our own evaluation of a mouse line that expresses Cre-recombinase under the control of the advillin promotor revealed region-selective efficiency differences in targeting tuft cells. Recombination rates were highest in the gall bladder, and rather low in stomach, small and large intestine. Hence, the applicability of the Avil-Cre mouse line to genetically target tuft cells must be critically reflected before time-consuming experiments are planned and performed. At least biliary tuft cells, and the related tracheal brush cell (see above) resemble valuable and promising targets. Nevertheless, we now propose that Avil-Cre mice can be added to this armory and may serve as a versatile tool to genetically target primarily biliary tuft cells in the mouse alimentary tract. The availability of an inducible variant of Avil-Cre, i.e. the Avil-CreERT mouse line (Hunter et al. 2018; Lau et al. 2011), would even allow genetic manipulation of tuft cell components on demand.

Acknowledgements Open Access funding provided by Projekt DEAL. We thank Dr. Ichiro Matsumoto (Monell Chemical Senses Center, Philadelphia, PA, USA) for sharing the Pou $23^{-/-}$mouse line. Prof. Jan Siemens (Institute for Pharmacology, Ruprecht-Karls-University, Heidelberg, Germany) is acknowledged for providing Avil-Cre mice. This work was funded by the German Research Foundation to BS (SCHU1259/10-1) and to WK (KU 688/8-1).

\section{Compliance with ethical standards}

Conflict of interest The authors declare that they have no conflict of interest. 
Open Access This article is licensed under a Creative Commons Attribution 4.0 International License, which permits use, sharing, adaptation, distribution and reproduction in any medium or format, as long as you give appropriate credit to the original author(s) and the source, provide a link to the Creative Commons licence, and indicate if changes were made. The images or other third party material in this article are included in the article's Creative Commons licence, unless indicated otherwise in a credit line to the material. If material is not included in the article's Creative Commons licence and your intended use is not permitted by statutory regulation or exceeds the permitted use, you will need to obtain permission directly from the copyright holder. To view a copy of this licence, visit http://creativecommons.org/licenses/by/4.0/.

\section{References}

Bezençon C, Fürholz A, Raymond F, Mansourian R, Métairon S, Le Coutre J, Damak S (2008) Murine intestinal cells expressing Trpm5 are mostly brush cells and express markers of neuronal and inflammatory cells. J Comp Neurol 509:514-525. https://doi. org/10.1002/cne. 21768

Bezençon C, le Coutre J, Damak S (2007) Taste-signaling proteins are coexpressed in solitary intestinal epithelial cells. Chem Senses 32:41-49. https://doi.org/10.1093/chemse/bj1034

Bjerknes $\mathrm{M}$ et al (2012) Origin of the brush cell lineage in the mouse intestinal epithelium. Dev Biol 362:194-218. https://doi. org/10.1016/j.ydbio.2011.12.009

Chuang YC, Lee CH, Sun WH, Chen CC (2018) Involvement of advillin in somatosensory neuron subtype-specific axon regeneration and neuropathic pain. Proc Natl Acad Sci USA 115:E8557E8566. https://doi.org/10.1073/pnas.1716470115

Deckmann K et al (2014) Bitter triggers acetylcholine release from polymodal urethral chemosensory cells and bladder reflexes. Proc Natl Acad Sci USA 111:8287-8292. https://doi.org/10.1073/ pnas. 1402436111

Eberle JA, Richter P, Widmayer P, Chubanov V, Gudermann T, Breer $\mathrm{H}$ (2013) Band-like arrangement of taste-like sensory cells at the gastric groove: evidence for paracrine communication. Front Physiol 4:58. https://doi.org/10.3389/fphys.2013.00058

Finger TE, Kinnamon SC (2011) Taste isn't just for taste buds anymore F1000. Biol Rep 3:20. https://doi.org/10.3410/B3-20

Gerbe F et al (2011) Distinct ATOH1 and Neurog3 requirements define tuft cells as a new secretory cell type in the intestinal epithelium. J Cell Biol 192:767-780. https://doi.org/10.1083/jcb.201010127

Giraldo P, Montoliu L (2001) Size matters: use of YACs, BACs and PACs in transgenic animals. Transgenic Res 10:83-103. https:// doi.org/10.1023/a:1008918913249

Hasegawa H, Abbott S, Han BX, Qi Y, Wang F (2007) Analyzing somatosensory axon projections with the sensory neuron-specific Advillin gene. J Neurosci 27:14404-14414. https://doi. org/10.1523/JNEUROSCI.4908-07.2007

Hass N, Schwarzenbacher K, Breer H (2007) A cluster of gustducinexpressing cells in the mouse stomach associated with two distinct populations of enteroendocrine cells. Histochem Cell Biol 128:457-471. https://doi.org/10.1007/s00418-007-0325-3

Howitt MR et al (2016) Tuft cells, taste-chemosensory cells, orchestrate parasite type 2 immunity in the gut. Science 351:1329-1333. https://doi.org/10.1126/science.aaf1648

Hunter DV, Smaila BD, Lopes DM, Takatoh J, Denk F, Ramer MS (2018) Advillin is expressed in all adult neural crest-derived neurons. eNeuro. https://doi.org/10.1523/ENEURO.0077-18.2018

Höfer D, Drenckhahn D (1992) Identification of brush cells in the alimentary and respiratory system by antibodies to villin and fimbrin. Histochemistry 98:237-242. https://doi.org/10.1007/ bf00271037

Höfer D, Drenckhahn D (1996) Cytoskeletal markers allowing discrimination between brush cells and other epithelial cells of the gut including enteroendocrine cells. Histochem Cell Biol 105:405-412

Höfer D, Püschel B, Drenckhahn D (1996) Taste receptor-like cells in the rat gut identified by expression of alpha-gustducin. Proc Natl Acad Sci USA 93:6631-6634. https://doi.org/10.1073/ pnas.93.13.6631

Iseki S (1991) Postnatal development of the brush cells in the common bile duct of the rat. Cell Tissue Res 266:507-510

Kaske S, Krasteva G, König P, Kummer W, Hofmann T, Gudermann T, Chubanov V (2007) TRPM5, a taste-signaling transient receptor potential ion-channel, is a ubiquitous signaling component in chemosensory cells. BMC Neurosci 8:49. https://doi. org/10.1186/1471-2202-8-49

Krasteva G et al (2011) Cholinergic chemosensory cells in the trachea regulate breathing. Proc Natl Acad Sci USA 108:9478-9483. https ://doi.org/10.1073/pnas.1019418108

Kusumakshi $\mathrm{S}$ et al (2015) A binary genetic approach to characterize TRPM5 cells in mice. Chem Senses 40:413-425. https://doi. org/10.1093/chemse/bjv023

Lau J, Minett MS, Zhao J, Dennehy U, Wang F, Wood JN, Bogdanov YD (2011) Temporal control of gene deletion in sensory ganglia using a tamoxifen-inducible Advillin-Cre-ERT2 recombinase mouse. Mol Pain 7:100. https://doi.org/10.1186/1744-8069-7-100

Luciano L, Reale E (1969) A new cell type ('brush cell') in the gall bladder epithelium of the mouse. J Submicrosc Cytol 1:43-52

Luciano L, Reale E (1992) The "limiting ridge" of the rat stomach. Arch Histol Cytol 55(Suppl):131-138

Marks PW, Arai M, Bandura JL, Kwiatkowski DJ (1998) Advillin (p92): a new member of the gelsolin/villin family of actin regulatory proteins. J Cell Sci 111(Pt 15):2129-2136

Matsumoto I, Ohmoto M, Narukawa M, Yoshihara Y, Abe K (2011) Skn-1a (Pou2f3) specifies taste receptor cell lineage. Nat Neurosci 14:685-687. https://doi.org/10.1038/nn.2820

McGinty JW et al (2020) Tuft-cell-derived leukotrienes drive rapid anti-helminth immunity in the small intestine but are dispensable for anti-protist immunity. Immunity 52:528-541.e527. https://doi. org/10.1016/j.immuni.2020.02.005

Misgeld T, Burgess RW, Lewis RM, Cunningham JM, Lichtman JW, Sanes JR (2002) Roles of neurotransmitter in synapse formation: development of neuromuscular junctions lacking choline acetyltransferase. Neuron 36:635-648. https://doi.org/10.1016/s0896 $-6273(02) 01020-6$

Muzumdar MD, Tasic B, Miyamichi K, Li L, Luo L (2007) A global double-fluorescent Cre reporter mouse. Genesis 45:593-605. https ://doi.org/10.1002/dvg.20335

Nadjsombati MS et al (2018) Detection of succinate by intestinal tuft cells triggers a type 2 innate immune circuit. Immunity 49:33-41. e37. https://doi.org/10.1016/j.immuni.2018.06.016

O'Leary CE, Schneider C, Locksley RM (2018) Tuft cells-systemically dispersed sensory epithelia integrating immune and neural circuitry. Annu Rev Immunol. https://doi.org/10.1146/annurevimmunol-042718-041505

Panneck AR et al (2014) Cholinergic epithelial cell with chemosensory traits in murine thymic medulla. Cell Tissue Res 358:737-748. https://doi.org/10.1007/s00441-014-2002-x

Perniss A et al (2020) Chemosensory cell-derived acetylcholine drives tracheal mucociliary clearance in response to virulence-associated formyl peptides. Immunity 52:683-699.e611. https://doi. org/10.1016/j.immuni.2020.03.005

Rhodin J, Dalhamn T (1956) Electron microscopy of the tracheal ciliated mucosa in rat. Z Zellforsch Mikrosk Anat 44:345-412. https ://doi.org/10.1007/bf00345847 
Schütz B et al (2015) Chemical coding and chemosensory properties of cholinergic brush cells in the mouse gastrointestinal and biliary tract. Front Physiol 6:87. https://doi.org/10.3389/fphys .2015 .00087

Schütz B, Ruppert AL, Strobel O, Lazarus M, Urade Y, Büchler MW, Weihe E (2019) Distribution pattern and molecular signature of cholinergic tuft cells in human gastro-intestinal and pancreaticbiliary tract. Sci Rep 9:17466. https://doi.org/10.1038/s4159 8-019-53997-3

Schütz B, von Engelhardt J, Gördes M, Schäfer MK, Eiden LE, Monyer $\mathrm{H}$, Weihe E (2008) Sweat gland innervation is pioneered by sympathetic neurons expressing a cholinergic/noradrenergic cophenotype in the mouse. Neuroscience 156:310-318. https://doi. org/10.1016/j.neuroscience.2008.06.074

Sutherland K, Young RL, Cooper NJ, Horowitz M, Blackshaw LA (2007) Phenotypic characterization of taste cells of the mouse small intestine. Am J Physiol Gastrointest Liver Physiol 292:G1420-1428. https://doi.org/10.1152/ajpgi.00504.2006

Trier JS, Allan CH, Marcial MA, Madara JL (1987) Structural features of the apical and tubulovesicular membranes of rodent small intestinal tuft cells. Anat Rec 219:69-77. https://doi.org/10.1002/ ar.1092190112

von Engelhardt J, Eliava M, Meyer AH, Rozov A, Monyer H (2007) Functional characterization of intrinsic cholinergic interneurons in the cortex. J Neurosci 27:5633-5642. https://doi.org/10.1523/ JNEUROSCI.4647-06.2007

von Moltke J, Pepper M (2018) Sentinels of the type 2 immune response. Trends Immunol 39:99-111. https://doi.org/10.1016/j. it.2017.10.004

Yamamoto Y, Ozawa Y, Yokoyama T, Nakamuta N (2018) Immunohistochemical characterization of brush cells in the rat larynx. $\mathrm{J}$ Mol Histol 49:63-73. https://doi.org/10.1007/s10735-017-9747-y

Yamashita J, Ohmoto M, Yamaguchi T, Matsumoto I, Hirota J (2017) Skn-1a/Pou2f3 functions as a master regulator to generate Trpm5expressing chemosensory cells in mice. PLoS ONE 12:e0189340. https://doi.org/10.1371/journal.pone.0189340

Zurborg S et al (2011) Generation and characterization of an Advillin-Cre driver mouse line. Mol Pain 7:66. https://doi. org/10.1186/1744-8069-7-66

Publisher's Note Springer Nature remains neutral with regard to jurisdictional claims in published maps and institutional affiliations. 